INTERNATIONAL DESIGN CONFERENCE - DESIGN 2018

https://doi.org/10.21278/idc.2018.0550

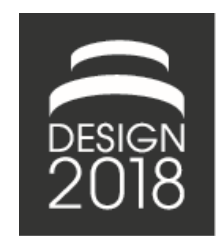

\title{
DESIGN METHODOLOGY: WHERE DO YOU GO?
}

\author{
P. Badke-Schaub and E. Voute
}

\begin{abstract}
Currently society undergoes disruptive changes so that the pressure on the designer in terms of MORE/BETTER/FASTER seems to be much higher than the centuries before. This contribution aims to initiate a discussion on how to gain a better understanding of what kind of design methodology should be offered to the designer to make him answer to these challenges. Especially the statement is made that there are so many empirical results about design behaviour which are not used - but would be useful to be implemented in design methodology - instead, we always start from the scratch again.
\end{abstract}

Keywords: human behaviour, design creativity, design methodology

\section{Introduction}

The field of Design Methodology yields a vast variety of approaches - developed in academia and in industry. New approaches appear and claim that they serve the designer better compared to the oldfashioned, traditional, rigid and prescriptive design methodologies. However, these claims are not underpinned by scientific data, there is no convincing amount of empirical studies comparing different methodological approaches and their influence on the process and the result in a scientific way. Few exceptions can be mentioned (see for example Daalhuizen, 2014) and even here the scientific rigor is partly doubtful.

Generally spoken, the indication for the general use of methods is scientifically not yet given - in pharmacology this treatment would have to spend more time and money to prove its specific impact. Thus, the request that designers should use methods to reach a better (whatever 'better' may be) output, is partly based on single case studies. There is a need for a systematic empirical study across different design situations and moments. An activity-pattern oriented overview or evaluation across methodologies would be laborious (Günther and Ehrlenspiel, 1999) and partly based on assumptions or individual observations. To be clear about it, we need to learn further details of successful bits and pieces of design methodology in many different environments.

From a designer's perspective, design methodology should support him/her to meet the demands of projects, where numerous actors, within a highly complex environment, are involved. Increasing complexity does not only refer to new technologies but also to new processes which have to be generated to adapt to the changes in procedures in the daily work. Both challenges do not only add additional demands related to acquisition and communication in information search and information transfer processes, but also require a more conscious and reflective way of designing in a transdisciplinary context (Gericke and Blessing, 2011; Greer, 2017).

Focusing on these challenges the aim of this contribution is to ask what is the use of Design Methodology for the designer in practice? From the beginning of the Design Methods Movement this question was brought up as the main challenge for Design Methodology about 50 years ago (Jones, 1970). Although initiated by designers in practice (Pahl and Beitz, 1977) design methodology was 
criticized for not meeting the demands of its users, the designers. In fact, the criticism refers to the same problems which are mentioned today: is design methodology useful. The indication are design problems which cannot be solved by the existing knowledge and routines, which do not have an optimal solution and are consisting of many actors involved with little common understanding about the final design. In the second part of this contribution we will ask what makes Design Methodology supporting design processes and designers. What need to be done to 're-vive' Design Methodology and to increase the trust of the designer into Design Methodology. Are there convincing empirical studies providing knowledge on the limitations and benefits of design methodology? What is the main stream of arguments? Are different research approaches needed to gain valuable, reliable and valid results? Do we address the right questions? What are the relevant factors of human behavior which shall be taken into account for a useful Design Methodology in industry?

The third chapter then will ask how far new approaches enhance the relevance and acceptance of Design Methodology in practice. Finally we will focus on the question about the possible intake of knowledge from different disciplines. What are unused pieces of knowledge that are necessary, because they are of huge value for supporting the designers' thinking and acting?

\section{Design methodology: Burden or blessing for the designer?}

At this moment, it shall be stated that we will not go into discussion about different views on definitions of design, design methods or design methodology. The usual result of such presentations is that there is no common definition, instead there are many forms of which only few are overlapping and that there is no satisfying definition of design methodology or design method.

Many authors discuss the question to define designing, but a common definition will not be a result of the discussion. Elaboration on definitions of the terms 'method' and 'methodologies' can be found for example in papers of Cross $(1991,1994)$ and papers of Gericke et al. $(2009,2012,2013)$. However, as there are some more terms which are often used in the same context, we refer to these differences by positioning the terms on a scale of concrete - and abstractness as can be seen in Figure 1.

\section{From abstract and general to concrete and specific}

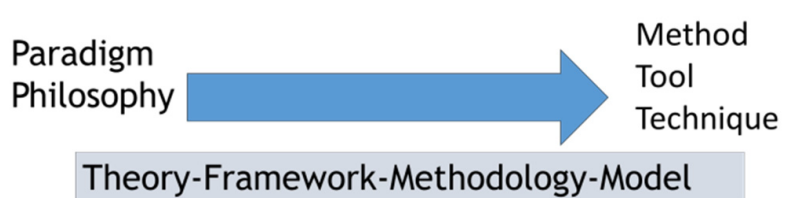

Figure 1. Terms on a scale from abstract to concrete and from general to specific

What seems to be relevant and common to all descriptions or definitions of 'designing' is named as 'the challenge by the increasing complexity in technology' which affects all design disciplines equally - but these changes do not only require more and different knowledge, they also add new requirements on the already complex design situation. And it is not only the increasing complexity of knowledge itself and new technologies which challenges the need for more creative thinking in order to arrive at successful and sustainable solutions. Moreover, the daily work routines are often not suitable anymore, because the way of communication and the way of eliciting, storing and transferring knowledge has changed in a significant manner (Badke-Schaub et al., 2005). Comparing design methodologies and process models across disciplines (Gericke and Blessing, 2011) found, on the basis of a literature study, that on an "abstract level design process models have a generic core of common stages". This seems to be a result which has been found already almost 20 years ago. Cross (2004) analysed the relationship between design methodologies in different disciplines, such as architecture, industrial design and mechanical engineering over the past decades. He also found that there was a huge similarity between the early design process models from the 1960's and 1970's.

Thus, design methodology as prescriptive support for the designers' daily work has to encompass the potential influences of these changes and adapt, integrate or develop new approaches and build them into existing design methodologies. In addition, the methods have to be validated what might be very 
difficult, as very complex methods need to be cut in pieces and different parts of the method would be validated separately; the question will remain, in how far the sum of the pieces will be the same as the single parts of the model.

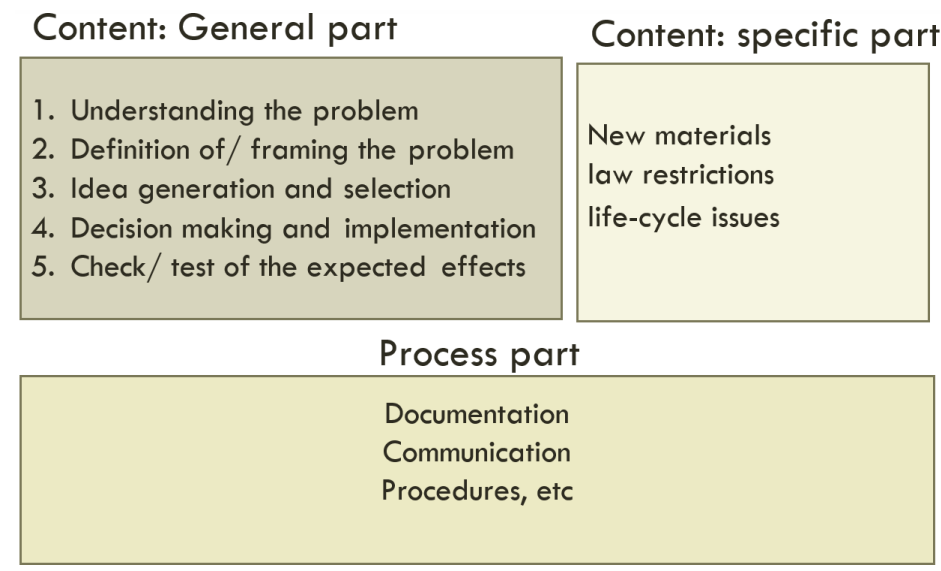

Figure 2. A complete methodology comprises three parts: the general content, the specific content and the process related part

\subsection{Comparing the use of different design methodologies}

How can we compare the use and thus the impact of a specific method/ methodology on the designer in regard to certain criteria?

For example, we might want to find out which method does lead to a more creative output or design solution. Let's assume we would compare VDI 2221 (Verein Deutscher Ingeniuere, 1984) and Design thinking (Brown, 2012). Whereas design thinking is more a framework or even a philosophy with a very low-resolution level on the activity site, the VDI approach asks for a detailed procedure with clearly defined outcomes after each phase.

There occur three major difficulties when we intend to scientifically measure and compare different methods:

- Which are the criteria to decide that a method has been used?

- How can we decide about the generalization of a method?

- How can we decide which learning processes occur when applying which design methods?

\subsection{Design activities}

As mentioned before, there are new approaches claiming to be effective and efficient. A new approach with the provocative title "Forget about the process" has been brought up recently by the Stanford d.school (2017). This model replaces the five hexagons model, which were according to the authors too much related to the process by design- relevant activities. These activities are:

Table 1. Abilities (left column) referred to as prerequisite for Design Thinking, as the current concept of the Stanford d.school, the two columns to the right are added by the authors

\begin{tabular}{|l|l|l|}
\hline Activity - Ability & Requirements of the cognitive system & Basic Category \\
\hline Navigate ambiguity & Dealing with uncertainty & Personality \\
\hline Learn from others (people and contexts) & Open mindedness & Personality \\
\hline Synthesize information & Systems view & Cognition \\
\hline Rapidly experiment & Cognitive flexibility & Cognition \\
\hline Move between concrete and abstract & Cognitive flexibility & Cognition \\
\hline Design your design work & Planning & Cognition \\
\hline Build and craft intentionally & Extend representation & Cognition \\
\hline Communicate deliberately & Ability to communicate & Interaction \\
\hline
\end{tabular}


The $2^{\text {nd }}$ and $3^{\text {rd }}$ columns are added by the authors using these "prescriptive abilities" (the reason for choosing just these eight abilities is not explained) but it seems that these abilities are chosen from the experience of the teachers of Stanford d.school and more than half of them are related to cognition aspects. Furthermore, the new model faces the same problem as the former design process models with a focus on steps, stages and phases. Apart from that these activities - at least most of them - are not operational and thus can be investigated more easily in a scientific way.

However, the approach to address specific activities instead of phases and stages and thus focus on how to realise these activities in a certain context most successful can be a promising approach. It is more easy to teach what needs to be done when the activity can be described as a defined behavior.

\subsection{Design context}

Following the abilities approach (Table 1) there is still a big part of the design process not described or defined - the context. The context can be differentiated at least into four main categories (see Figure 3), which are summarised under 'other involved stakeholders (the main perspective), the use of methodological approaches, the human resources involved and the societal perspective. Whereas the two categories 'methodological approaches and human resources are deemed to reduce complexity, the 'social perspectives' and the other involved stakeholders increase complexity. This kind of model has two advantages: First, it ensures that the designer does reflect on the complexity he is in, further on, it helps to not ignore certain fields of context or fixate on one topic.

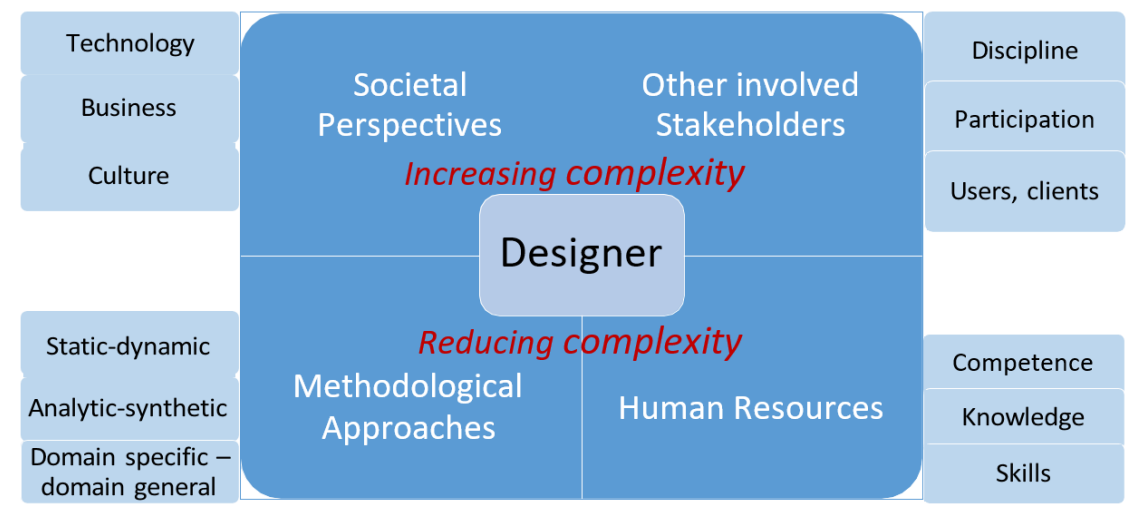

Figure 3. Categories of different context settings within the designer needs to operate

Of course, there is an in depth analysis necessary about how to bring these models to an empirical study. It could also be thought to marry both models and to define important patterns of activities in various context settings.

\section{Design methodology: Where to go?}

In summary, we can state that Design Methodologies have some common characteristics and some common limitations and there are also differences on different levels of abstraction which influence designing in different ways. Newer approaches seem to be less detailed (see for example Brown, 2009; Dorst, 2015). 'New' design approaches present a more idealistic view, which is formulated on a rather low resolution level. Further on there is no scientific based proof which of the characteristics are the more important ones - important is meant as relevant in terms of goal attainment. Furthermore, none of these approaches has been empirically proven; they are a generalization of own experiences (what is very similar to the traditional methodologies) stressing the relevance of activities such as collaboration, exploring and integrating options, low-fidelity prototyping and interpretation - which mostly are not design-specific.

\subsection{Scientific knowledge gained from empirical design research}

Design research is getting more and more a scientific discipline with a high increase of empirical studies. And there is a big amount of results from other disciplines such as human sciences. 
If design methodology is aiming to support the designer it is obvious that there is a primary need to understand the designers' thinking and acting behavior before further support can be derived.

Looking at the kind of assumptions about the designers' visualizations of the design process (see as an example Figure 4), it seems to be of specific interest. There are many authors visualizing the design process, or better they visualize a process which they see as the design process.

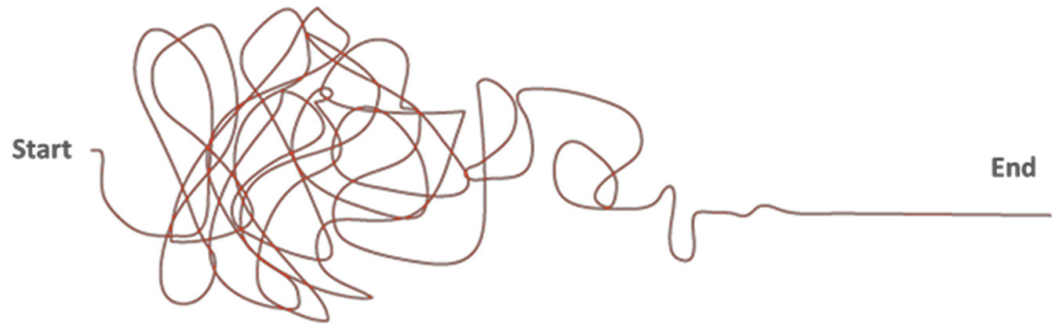

Figure 4. Schematic visualization of a design process

It is assumed that a design process can be completely unstructured (see Figure 4). And some of these pictures start with the 'zero assumption' of the designers' brain. Meaning, the designer jumps into a design problem/ project without any knowledge or structure. This is very unlikely and it has been shown that especially experienced designers have a multitude of possible solutions to each kind of problem in their memory; they react on stimuli, which seem to be relevant, with a hypothesis derived from their own mental model. Depending on the familiarity with the topic this model can be more or less concrete, it can be more or less correct, etc. but what is most important, it allows- instant reactions. Also in situations which are new and unclear each person constructs hypotheses what might happen next and how this will influence the current situation. In any case there will be no trial and error behavior.

The following five examples have been chosen which illustrate the challenge of understanding the designer in his/her natural context.

\subsubsection{Beyond the individual designer: the Team}

The current multiplayer complex working situation of the designer force him/her to work together with different people, in different competitions, in different projects; the genius single designer is not the one who is in the focus of daily design projects. There needs to be a shift in attention, for design support, a shift from the individual designer to the individual designer in the team and the team itself. However, these shifts should not ignore the individual designer because there are also relevant characteristics which lead to specific design behavior such as experience and intuition.

\subsubsection{Beyond rationality: Intuition}

What kind of processes and/or activities do we portray when we talk about intuition? Intuition is not directly observable by another person, and also the acting person him/herself has, according to most empirical findings, intuition that is based on, over many years accumulated, experience using reasoning and rational thinking processes to structure and evaluate information. After some time, the person has established a kind of mental model about the content, which provides-also in new situations that come up - instant responses without any use of conscious deliberations (Badke-Schaub and Eris, 2014). This behavior of designers should be a part of in any kind of design methodology as it can be helpful in terms of quick reactions but also limiting because of wrong answers. There is a general assumption that Design methodology supports rational decision making but ignores processes and/or activities based on experience based intuition.

\subsubsection{Beyond top down structured processes: Opportunistic behaviour}

The structuring of Design methodology is based on top-down processes of goals and sub-goals, and the sequence is ordered according to goal specificity. Empirical data show that designers more often choose opportunities when these come up, that are not supported by Design Methodology. 


\subsubsection{Beyond strategies: Thinking in solutions}

Instead of a strict division between co-evolution and task clarification, as is suggested by the traditional design methodology, designers starts with the goal analysis and only after the problem is clear the designer should start with the generation of ideas.

\subsubsection{Beyond resources: Time}

Time is a neglected factor in traditional design methodologies. Time pressure urges for acceleration of internal cognitive processes to speed up or to maintain the speed of external processes during the design project. Human beings have problems with time. On the one hand human beings can't estimate time system. Thus, support could be very helpful for the designer to base his activities on a reliable time estimation.

\subsubsection{Beyond ill-defined problems}

The definition of a problem as well- or ill-defined was an important step in the process of the finding that problems can have very different characteristics and thus different challenges. However, these descriptions are very general but nevertheless not integrated in traditional design methodologies. Other approaches such as Cinefin, a conceptual framework, was introduced in the early 2000s within IBM offers five decision-making contexts: simple, complicated, complex, chaotic, and disorder; the identification influences the way how situations are perceived and determine leader' behavior. and to make sense of their own and other people's behavior.

\subsection{Gaining knowledge from other disciplines}

Without claiming comprehensiveness, the model provides a categorisation for the context of the designer, who is the actor in a multidimensional field (see Figure 3) with lots of influencing factors which the designer faces when designing. These four categories refer to two fundamental different strategies, reducing or enhancing complexity. Both strategies are necessary, and equal the diamond model, which describes designing as switch between analysis and synthesis.

Two concepts will be referred to which have gained a lot of attention in social sciences as human capabilities influencing the own behavior, the ability of dealing with uncertainty, and the ability to reflect on the own behavior.

\subsubsection{Dealing with uncertainty}

Cognitive processes are mainly influenced by the knowledge and capacities of the individual memory but the motivational and emotional state of the person. Situations with a high degree of complexity, also often named 'ill-defined problems' (Simon, 1973), or wicked problems (Rittel and Webber, 1972) which cannot be solved by the existing knowledge and which do not have an optimal solution, lead to uncertainty. If we assume that uncertainty provides structure then we also could assume that people want to avoid staying in a situation of uncertainty but rather a structured state. If we assume that design methodology can structure the process and thus reduce uncertainty for the individual designer but also the uncertainty of the other participants, we can make teams work productively.

\subsubsection{Reflecting own behavior}

The ability to reflect on the own behaviour is a powerful instrument allowing humans to flexibly adapt to different situations and changes in their environment. There is no single behaviour or strategy that has been proven successful to recognize failures or other issues which prevent successful behaviour (Dörner, 1978). Thus, reflexion is a crucial success factor in dealing with complex situations such as design projects. Reflection occurs very seldom naturally but it can be taught as a kind of meta-cognitive skill. Two ways of reflection can be distinguished, first as an analysis of how the person dealt with a given situation, as an analysis of the own thoughts and actions, 'reflection on action' And second, Schön formulated the idea of design as a reflective conversation with the materials of a given situation, what he called 'reflection in action' (Schön 1983, 1990). 


\title{
4. Conclusions
}

Design methodology was never as important as it is nowadays. Coping with very complex problems, many stakeholders in an interdisciplinary setting with many disciplines involved, Design Methodology can be used in different ways to structure content and process of problems which received names such as ill- defined problems (Simon, 1973), wicked problems (Rittel and Webber, 1973) and complex problems (Dörner and Schaub, 1994) which all cannot be solved by the existing knowledge and which do not have an optimal solution. Design Methodology is necessary for structuring processes amongst groups and individuals, to make teams work productively. Design methodology can reach more acceptance of designers in industry when the support can be integrated into the designer's working style, strategies and priorities.

Designing is an activity involving multiple disciplines, many stakeholders such as users, clients, suppliers, manufacturers, distributors, consumer/customer, and other agencies. There are new challenges for the new designer and there is a need for a broader profile.

Moreover the complexity of the context should not be neglected. Using the model (Figure 3) different patterns of complexity can be chosen and these can stand for certain combinations of characteristics of different working styles which demand specific answers to that situation which will be realised by softand hardware. For example, if the software or the design robot realises contradictions in the planning of the project or in regard to the goal definition it is likely that she will intervene and will suggest further procedures or even will come up with different kinds of solutions. Thus computers will reduce the complexity for the designer. But still we don't know whether this will improve the use of design methodology - and even if so - what then will be the designer designing? And how does this situation attack the health of the designer?

And finally, an answer to the most important question: Why is Design Methodology important for our future? At first, the presentation of Design Methodologies will be much more sophisticated, it will stepby-step take over the lead in the design process and use all different kinds of approaches to structure the designers' world. It will be more strict than the designer ever thought about. It will be quick, it will be rational and it will be non- sexist.

Secondly, - now a longer quote is given and we encourage the reader to guess who the owner of this text is. The quote is taken from one of the early protagonists of the Design methods Movement.

Designing will be relevant:

\begin{abstract}
"as the process of devising not individual products but whole systems or environments such as airports, transportation, hypermarkets, educational curricula, broadcasting schedules, welfare schemes, banking systems, computer networks;

as participation, the involvement of the public in the decision-making process;

as creativity, which is supposed to be potentially present in everyone;
\end{abstract}

as an educational discipline that unites arts and science and perhaps can go further than either;

without a product, as a process or way of living in itself."

\section{References}

Badke-Schaub, P. and Eris, O. (2014), “A Theoretical Approach to Intuition in Design: Does Methodology Need To Account for Unconscious Processes?” In: Chakrabarti, A. and Blessing, L. (Eds.), An Anthology of Theories and Models of Design, Springer, London, pp. 353-370. https://doi.org/10.1007/978-1-4471-6338-1_17

Badke-Schaub, P., Lloyd, P., van der Lugt, R. and Roozenburg, N. (2005), "Human-centered Design Methodology", In: Achten, H.H., Dorst, K., Stappers, P.J. and de Vries, B. (Eds.), Design Research in the Netherlands 2005, Technische Universiteit Eindhoven, Eindhoven, pp. 23-31.

Birkhofer, H. (2011), The Future of Design Methodology, Springer, Heidelberg. https://doi.org/10.1007/978-085729-615-3

Birkhofer, H., Kloberdanz, H., Sauer, T. and Berger, B. (2002), "Why methods don't work and how to get them to work." Proceedings of the Engineering Design in Integrated Product Development, 3rd International Seminar and Workshop (Design methods that work), Zielona Gora, Lagow, Poland, October 10-12, 2002, pp. 29-36.

Brown, T.N. (2009), Change by Design, NY, HarperCollins Publishers Inc.

Daalhuizen, J. (2014), Method usage in design, PhD thesis, TU Delft, NL. 
Daalhuizen, J., Badke-Schaub, P. and Batill, S. (2009), "Dealing with Uncertainty in Design Practice: Issues for Designer-Centered Methodology", Proceedings of ICED'09 / the 17th International Conference on Engineering Design, Vol. 9, Human Behavior in Design, Palo Alto, CA, USA, August 24-27, 2009.

Dörner, D. (1972), Problemloesen als Informationsverarbeitung, Kohlhammer, Stuttgart.

Dörner, D. (1978), "Self-Reflection and Problem Solving”, In: Klix, F. (Ed.), Human and Artificial Intelligence, Deutscher Verlag der Wissenschaften, Berlin, pp. 101-107.

Dörner, D. and Schaub, H. (1994), "Errors in planning and decision-making and the nature of human information processing", Applied Psychology: An International Review, Vol. 43 No. 4, pp. 433-453. https://doi.org/10.1111/j.1464-0597.1994.tb00839.x

Dorst, K. (2015), Frame Innovation: Create New Thinking by Design, The MIT Press, Cambridge.

Gericke, K. and Blessing, L. (2011), "Comparisons of design methodologies and process models across disciplines. A literature review”, Proceedings of ICED'11 / the 18th International Conference on Engineering Design, Impacting Society through Engineering Design, Vol. 1: Design Processes, Lyngby/Copenhagen, Denmark, August 15-19, 2011, pp. 393-404.

Gericke, K., Eckert, C. and Stacey, M. (2017), “What do we need to say about a design method?", Proceedings of ICED'17 / the 21st International Conference on Engineering Design, Vol. 7: Design Theory and Research Methodology, Vancouver, Canada, August 21-25, 2017, The Design Society, Glasgow, pp. 101-110.

Greer, K.R.C. (2008), Thinking networks - the Large and Small of it: Autonomic and Reasoning Processes for Information Networks, Createspace.

Günther, J. and Ehrlenspiel, K. (1999), "Comparing designers from practice and designers with systematic design education”, Design Studies, Vol. 20 No. 5, pp. 397-494. https://doi.org/10.1016/S0142-694X(99)00019-8

Jones, J.C. (1970), Design methods, John Wiley \& Sons, Chichester.

Pahl, G. and Beitz, W. (1977), Konstruktionslehre, Springer, Berlin.

Sawyer, R.D. (1993), The Seven Military Classics of Ancient China, Westview Press, Boulder, Colorado.

Schön, D.A. (1983), The Reflective Practitioner. How Professionals Think in Action, Basic Books, New York.

Schön, D.A. (1990), Educating the Reflective Practitioner, Jossey-Bass, Oxford.

Simon, H. (1973), "The structure of ill-defined problems", Artificial Intelligence, Vol. 4 No. 3-4, pp. $181-201$. https://doi.org/10.1016/0004-3702(73)90011-8

Stanford d.school (2017), Let's stop talking about THE design process. [online] A Medium Corporation. Available at: https://medium.com/stanford-d-school/lets-stop-talking-about-the-design-process-7446e 52c13e8 (accessed 19.03.2018).

Verein Deutscher Ingenieure (1989), Approach to the Design of Technical Systems and Products, VDI 2221.

Wetzstein, A. and Hacker, W. (2004), "Reflective Verbalization improves solutions: The effects of question-based reflection in design problem solving", Applied Cognitive Psychology, Vol. 18 No. 2, pp. 145-156. https://doi.org/10.1002/acp.949

Prof. Petra Badke-Schaub

Delft University of Technology, Industrial Design Engineering

Landbergstraat 15, 2628 CE Delft, Netherlands

Email: P.G.Badke-Schaub@tudelft.nl 